\title{
COMPUTER SYSTEMS AND TECHNOLOGIES
}

\section{Medvediev M. H.}

\section{The emergence of information technology}

The notion of "information technology" arose in the last decades of the XX century in the process of formation of computer science. The peculiarity of information technology is that in it both the subject and the product of work are information, and instruments of labor - the means of computer technology and communication. Information technology as a science of information production arose precisely because information was considered to be a completely real production resource, along with other material resources. At the same time, the production of information and its top-level - knowledge - has a decisive influence on the modification and creation of new industrial technologies. By information technologies means the whole set of forms, methods and means of automation of information activities in various spheres. To date, the general theory of information technology (IT) as a system of integral interconnected techniques, methods and means of information processing has not been developed, the basic concepts of IT are not defined. However, it is enough to understand the essence of IT, as well as explain its scientific and practical importance. Moreover, the design and creation of specific IT intertwines many tasks from various scientific disciplines ${ }^{1}$.

As a science, IT includes methodological and methodological provisions, organizational settings, methods of using instrumental and technical means - all that regulates and supports the information production and activities of people involved in this production. The transformation of new scientific knowledge into specific information technology is the main task of IT as a science.

In view of the discussion of the subject of discussion, we give a few notions of IT: a set of scientific methods and techniques for the production of information products and services with the use of all the diversity of computing facilities and communications; it is a border area that covers

\footnotetext{
${ }^{1}$ Vitkup M.E. Informatics and computer engineering (MSOffice in examples and problems with methods of their solution): Tutorial / M.E. Vitkup, V.V. Petrenko. К.: Центр «Методика-информ», 2002. 351 c.
} 
both computing technology and a specific social information practice that rationalized it at the expense of widespread use of computer technology; This is a collection of fundamentally new tools and methods that provide creation, processing, transmission, display and storage of information.

A huge impetus to the development of information technology brought the development of multimedia. From this point of view, information technology - a set of methods and methods for receiving, processing, presenting information aimed at changing its state, properties, form, content and carried out in the interests of users.

According to the definition of IT adopted by UNESCO, information technology is a complex of interrelated scientific, technological, engineering disciplines studying methods of efficient organization of labor of people engaged in the processing and storage of information; computer technology and methods of organization and interaction with people and industrial equipment, their practical applications, as well as all social, economic and cultural problems associated with them.

IT require complex training, large primary costs and high technology. Their introduction should begin with the creation of mathematical support, the formation of information flows in the training systems of specialists. Recently, the following terms have become widespread: paperless technology, interactive technology, programming technology, database design technology, CALS-technology (Continuous Acquisition and Lifecycle Sourror), network technology, Internet technology, technology for analysis and reengineering of business processes, etc. All of them assume the use of information, any kind of information about the objects, facts, concepts of the subject area.

There are three levels of information technology review: the first level is the theoretical. The main task - the creation of a complex of interrelated models of information processes, compatible with parameters and criteria. The second level is research. The main task - the development of methods that allow automated design of optimal concrete information technology; The third level is applied, which is divided into two parts: instrumental and substantive.

Instrumental part (analogue - equipment, machine tools) determines ways and means of realization of information technologies, which can be divided into: methodical; informational; mathematical; algorithmic; technical; software. 
The subject is connected with the specifics of a specific subject area and is reflected in specialized information technologies, for example, organizational management, technological process management, automated design, training and others.

Information technology provides a transition from routine to industrial methods and tools of work with information in various areas of human activity, providing the opportunity to use it rationally and effectively.

\subsection{Concept and components (structure) of information technologies}

Under information technology is understood a set of methods, production and software and technological tools, integrated into the technological chain, which provides for the collection, storage, processing, output and dissemination of information. Information technologies are designed to reduce the complexity of processes of using information resources.

Computer information technologies mean the use of computer facilities and network technologies for the implementation of a wide range of tasks: the preparation of text documents; creation of data banks, their processing and use; automation of financial and scientific calculations; making of books, newspapers, magazines; creating and editing graphic and photo images; creation of cartoons; creation of electronic encyclopedias and electronic versions of other books; creation and computer processing of sound; creation and computer processing of television and video; creation and use of telecommunication computer networks; computer design of various mechanisms, architectural structures, creation of geographic maps, etc.; modeling of natural, technical and other processes.

IT is an integral system that functions in a single information space due to the consistent work of all its components. Implementation of the system and its deployment in time provides the dynamics of information technology development, its modification, restructuring, joining of new components of the system and modernization. IT consists of interconnected components, which are grouped into three groups: basic technologies, specific technologies of $\mathrm{AE}$ (Application Environment) (enterprise, corporation, office, firm, etc.) and knowledge base of $\mathrm{AE}^{2}$.

AE displays in the database a collection of objects of the real world with their connections belonging to a certain field of knowledge and of

\footnotetext{
${ }^{2}$ Марк Спортак, Френк Паппас и др. Компьютерные сети и сетевые технологии. Platinum Edition: Пер. с англ./ СПб.: ООО «ДиаСофтЮП», 2005. 720 с.
} 
practical value to users. The subject area exists independently of both the creator of the IS and the IS itself.

The AE model is a certain system that mimics the structure and functioning of the research subject area and meets the basic requirements to be adequate to this area. The value of such models, such as reference ones, is that they reliably convey the specifics of the subject area, while the template model represents a solution to the problem in a defined context, but allows for use in other contexts.

Basic technologies - a set of hardware automation, system and application software, which implement the subsystem of storage and processing of information.

Knowledge Base $(\mathrm{KB})$ is a formal representation of a coherent, consistent compendium of judgments reflecting the knowledge of $\mathrm{AE}$. KB contains both a database (scheduled tasks, accounting, production, scientific, legislative, auxiliary information), as well as the user interface. The main form of organizing information on carriers is a database.

Data Base (DB) is a named set of structured data that reflects the state of objects and their relationships with such minimal redundancy, which allows it to be used for one or more applications in a certain AE.

\subsection{Information processes}

The notion of information is inseparable from the notion of information processes. Information processes include: information transfer; receiving information; storage of information; processing of information and its representation for use; use of information.

Information technologies can practically be implemented in nonautomated (traditional or, in other words, "paper"), and in an automated form.

The hardware components are a personal computer, office equipment, communication lines, network equipment. The software is directly dependent on the hardware and information support and implements the functions of accumulation, processing, analysis, storage, interface with the computer.

Infoware - a set of data presented in a certain form for computer processing. Data - information obtained by measurement, observation, logical or arithmetic operations, are presented in a form suitable for storage, transmission and processing. Organizational and methodical 
support is a set of measures aimed at the functioning of the computer and software for obtaining the desired result.

There is another approach to considering the structure of automated IT, according to which any IT can be divided into three interdependent and equivalent components that make up its core: hardware; software; brainware. In addition to the above mentioned core of the IT, there is another, very important component - the IT support network, Infrastructure - the necessary physical, administrative and organizational structures, cultural schemes, standards and criteria, and so on. The advocates of this approach believe that the merger or merger of information technology into larger structures - technology systems (using the term "information technology and systems" - IT/S) should be considered in practice.

However, the mere availability of the necessary components that make up IT (complexes of technical and software tools, as well as information and organizational and methodological support) is not enough to "revitalize" the technology. Implementation of IT is possible in a specific environment - the information system.

\subsection{Properties and classification of information technologies}

Among the properties of IT should indicate the following: expediency - increasing the efficiency of production based on the use of modern DEC, distributed information processing, distributed databases, various information networks (ICN) through the circulation of information and processing; the presence of components (specific content of processes of circulation and processing of information) and structures (internal organization, which are the interconnections of the components that make it, are grouped into two large groups: reference technology and knowledge base); interaction with the environment; integrity; development in time.

The classification of IT depends on the classification criterion. The criterion may be the indicator or a set of features that affect the choice of one IT or another. Different schemes of IT classification are possible. Each of them is based on certain classification characteristics.

The first sign of classification is the absence or availability of automation. In this case, here are traditional and automated technologies. Providing and functional information technology. 
Providing technologies can be used as tools in various subject areas for solving various problems. They can be classified according to the types of tasks that they solve. Examples of technology providing are text processing technologies, database management systems. Usually these technologies can be performed on different computers and in different software environments. The main task is combining these technologies into a single information system. Functional technologies are a set of providing technologies for the automation of some task, function. The technology of processing information on a computer can consist of a predefined sequence of operations and does not require the user to interfere in the processing process. In this case, the dialog with the user is null and the information will be processed in batch processing mode.

Tasks solved in batch mode, are characterized by the following: the algorithm for solving the problem is formalized, the process of its solution does not require human intervention; There is a large amount of incoming and outgoing data, much of which is stored on electronic media; the calculation is performed for most entries of the input files; big time solution to the problem due to large volumes of data; tasks are solved with a given periodicity. If you need a direct user interaction with a computer, where the user receives instantaneous computer actions for each of his actions, the dialogue mode of information processing is used.

Dialogue mode is the evolution of batch processing mode. Dialogue mode provides for the absence of a rigorous security operation with operational data, unless it is conditioned by the subject matter technology.

Next classification mark is the type of processed information.

Information is a set of known properties of an object or process, which are subjects of knowledge.

Information is a set of signals of physical processes, which are perceived by the subject through the organs of his senses.

All the information that a person uses, can be divided into the following types: mathematical is any information associated with numbers and formulas. In addition, in fact, mathematical, it can be both physical and statistical information. Mathematical information can be processed using various counting machines and apparatuses and stored on paper in the form of records and books; textual - this information can be written on paper by hand or by means of a PC and stored on paper (manuscripts, documents, books, newspapers, etc.) or electronic media; graphic - this information 
can be processed using various visual means and methods (fine arts, photography) or special graphic editors and stored in the form of paintings, drawings, sculptures, photographs, etc.; sound - this information can be processed with a tape recorder or special sound editors and stored on magnetic tapes, recorders and audio CDs and electronic media; video information - this information can be processed with motion picture and video equipment or video editing software and stored on film, video tapes and electronic media.

All these types of information existed before the computer appeared. A modern personal computer has allowed processing all these types of information and greatly facilitated their sharing.

Today, it is possible to combine different forms of information representation on a single media, thanks to multimedia technologies.

\section{History of CT development}

Automation of the processes of work naturally goes through several stages: partial mechanization, complex mechanization, partial automation and complex or complete automation. At present, CTs are divided to: CT 1 generation (1965-1975) - elemental base, discrete semiconductors, programmable media - magnetic tape (unitary code BCK-5), devices K-4MI, K2P (ZP), KPT; CT 2 generation (1966-1982) - an elemental base of chips of series 155,176 , a programmer - an eight-track punch tape (ISO-7 bit), devices N22, series P; CT 3 generation (1977-1989) - element base VIS of series 589 (software implementation of control algorithms, storage of programs in memory, expansion of technological functions), software - eight-track punch tape; KT 4 generation (1985-1990) - block multiprocessor implementation, specialized VIS, high-level languages for technological functions programming, electroautomatics, dialogue, programming - eight-track pistol (ISO-7 bit code), the ability to add a communication program to the computer; 5 generations $(1990-.$.$) -$ industrial PCs, multiprocessor systems.

At each stage of the development of science and production, a certain approach was applied, appropriate design solutions and elements were proposed. From the user's point of view, each improvement was directed, first of all, to the following: increasing the level of mechanization and automation of the implementation of frequently repeated technical 
operations; creation of new input and output tools; increase a memory space; the development of new data storage devices, etc.

Management of technological processes based on SCADA-systems began to be implemented in the leading western countries in the 80's of the twentieth century. In the 90 years of the last century began to appear software systems, through which any employee can observe the work of an arbitrary unit of equipment. These include the Factory Suite (Industrial Set) of the company "Wonderware" (USA) and Genesis (Revival) firm "Iconics" (USA). So, the Factory Suite consolidates the MES levels.

MRP - DBA Manufacturing, MRP Design Group, Ascent company, etc.

MES - Lighthouse Systems, KIS «Omega Production», Oracle E-Business Suite (OEBS)

SCADA - In Touch (Wonderware, USA), iFIX (Intellution, USA), SIMATIC WinCC (Siemens, Germany), Citect (Ci technologies, Australia), RTAP / plus (HP, Canada), Wizcon (PC Soft International, Israel- USA), Sitex and Phocus (Jade SoftWare, UK), Real Flex (BJ Software Systems, USA), Factory Link (US Data Corp., USA), View Star 750 (AEG, Germany), PlantScape (SCAN 3000) Honeywell, USA), Schneider Electric (France).

\section{Application and main purpose of computer technology (CT)}

CTs are best suited for automation of continuous and discrete processes, and are used in the following areas: production management; transmission and distribution of electricity; industrial production; water purification and water separation; management of space objects; transport management (all types of transport: air transportation, metro, railway, automobile, water); telecommunications; military industry.

In addition, the introduction of $\mathrm{CT}$ in medicine is perspective. In the world, there are more than a dozen companies that are actively engaged in the development and implementation of computer-integrated technologies in the medical sector, and software products of some of these companies are represented on the Ukrainian market.

The main objective of computer technologies is the creation and operation of computer integrated management systems that provide the solution of tasks of coordinating the operation of subsystems, the use of 
intelligent subsystems of decision support on the basis of databases and knowledge and management systems.

This kind of activity requires the knowledge of special software. At the same time, computer-integrated technologies are closely linked to systems of automatic control and automation of processes in various industries and production.

\subsection{Levels of computer-integrated production organization}

Computer-integrated production contains five levels of automation:

I/O (Input/Output) - the level of communication with the equipment. Here the coordination of external elements with the control device is provided.

Control - At the control level, the control devices built into the equipment control the signals of state-of-the-art sensors by producing control commands for actuators - drives, valves, lights and sound signals ${ }^{3}$.

$\mathrm{I} / \mathrm{O}$ and Control levels are sufficient to control the process equipment.

In the process of development of automation, the level of control of technological equipment and the level of organization of production became closer to each other. Now, simultaneously with the management information on the operation of equipment in real time is transmitted to the level of generalized control and SCADA data collection.

SCADA (Supervisory Control and Data Acquisition) - at the SCADA level, they sort, transform and store current data, as well as their mapping in the process mnemonic. For the controller, the behavior of all units of equipment is displayed: the current state and performance of machines, the movement of material flows, generalized information.

SCADA systems allow you to observe the process as a whole, track emergency information, time trends and statistical characteristics of the process. If necessary, the controller transfers generalized control commands to the equipment and can remotely reprogram the remote automation systems.

MRP (Manufactory Resources Planning) - resource planning level. This is a well-known version of office activities automation for the purpose of accounting, financial management and logistics, organization of document circulation. At this level, production managers analyze the

3 В.С. Билоусько, Т.И. Чуждан Вычислительные машины и программирование: Практикум / В.Е. Антипенский, К.: Вища шк. Головное изд-во, 1987. 245 с. 
market-oriented strategy: the dynamics of market prices for manufactured products, the level of profit for different types of products, and predict demand.

MES (Manufacturing Execution System) - an additional level of execution of tasks that connects top managers with current production. Here information from SCADA is converted into information for the MRP, the database is updated, the sequence of operations is monitored, the scheduling of inspection and repair of the equipment is formed depending on the duration of actual operation. After analyzing this information from the position of production and business policy of the enterprise strategic manager decisions are executed at lower levels.

In the 1990s, software systems that could receive information from any of the five levels of computer-integrated production began to emerge. The MRP top level manager can go to a lower level of automation to analyze the work of any unit of equipment. On the other hand, the debugger of the equipment at a lower level can, by going to the Internet through the upper level, get from the manufacturer from anywhere on the planet a troubleshooting instruction.

\subsection{Information systems (IS)}

Simultaneously with the widespread use of new information technologies, the concept "information system" (IS) appeared. Information System - (Computer-Based Information System) is a complex of computing and communication equipment, software, linguistic resources and information resources that provides for their collection, storage, updating, distribution and processing in order to support any kind of activity.

Consequently, IS is understood as a set of interconnected components that work together to achieve a certain goal. To describe the system, the following concepts are used: structure (set of elements and relationships between them); inputs and outputs (material, financial and information flows entering and outputting the system); laws of behavior (functions connecting inputs and outputs of the system); goals and constraints (the processes of the system being described by a number of variables, usually limited to individual variables).

Until now, the processing of economic information has been isolated in a separate independent scientific and technical direction, which is characterized by a huge variety of ideas and methods. At the same time, 
individual elements of the information processing process have reached a high level of organization and interconnection, which allows combining all means of information processing on a particular economic object with the notion of "Economic Information System".

An economic information system is a system whose functioning consists in collecting, storing, processing and disseminating information about the activities of any real economic object.

The main role of the economic information system is to organize the storage and transmission of information. Consequently, the implementation of the functions of the information system is impossible without an information technology oriented to it.

The economic information system is based on two components: system and information.

A system can be defined as a set of interconnected elements acting as a unit.

Information can be defined as a variety of new information that allows you to improve the processes associated with the transformation of matter, energy and information itself.

Management is a change in the state of the system, which leads to the achievement of the goal.

The process of control of the system is determined by the objectives of management, the environment and internal conditions.

From the standpoint of cybernetics, this process is interpreted as a directed action on the elements of the system to achieve the goal, and can be represented as an information process that relates the external environment, object and control switch.

The information exchange that underlies the process of managing the system consists in the cyclic implementation of the following procedures: collecting information about the current state of the controlled object; analysis of the received information and comparison of the current state of the object with the desired; developing a control action to convert the controlled object to the desired state; transmission of the control to the object.

The organizational structure of an economic object regulates the scheme of information flows of the management system, decisionmaking levels. Typical organizational structures are: 1) management information - a set of planning, regulatory and policy information, 
which is formed by the control switch (subject of management) in accordance with the purpose of management and information about the environment; 2) accounting and reporting information, which is formed by the object of management and reflects the internal state and degree of influence on the object of the environment; 3) information on the external environment - regulatory and legislative information created by government agencies, information on market conditions created by competitors, suppliers, consumers.

Flows of control information are sent from the subject to the object of management. The effectiveness of management is achieved through feedback - obtaining information about the current state of the controlled object. Based on the analysis of information flows, appropriate management decisions are made. Output information is intended for other objects of the economy, higher standing organizations: reporting financial information - for government agencies, investors, creditors, and so on; marketing information - for potential consumers. The basic elements on which the management system of the organization is based include: goals and strategies; business processes; organizational structure (management structure); ways of interaction (flows and communication); regulations and motivation (employees).

The task of developing a management system, improving its efficiency and the whole business in general, is to support each of its elements in the required state. An interconnected set of tools, methods, personnel used to store, process, and issue information in order to achieve the goal is the information system (IS).

With the development of computer technology, the meaning of information system changed. The modern information system is a set of information technologies aimed at supporting the lifecycle of information and includes three main processes: data processing, information management and knowledge management. In the context of a sharp increase in the volume of information, the transition to working with knowledge on the basis of artificial intelligence is probably the only alternative to the information society.

Thus, the information system is an organized, interconnected set of IT tools and techniques that are used to store, process, and issue information to achieve a specific goal. 
Implementation of IS improves the efficiency of production and economic activity of the enterprise due to not only processing and storage of information, automation of routine work, but also fundamentally new methods of management.

New methods of management are based on modeling the actions of specialists in decision making (methods of artificial intelligence, expert systems, etc.), using modern telecommunication facilities (e-mail, teleconferencing), global and local area computer networks.

The main ways of building an IS:

- development of the custom design system;

- use of prototypes - instead of a complete system, a prototype is created that meets the basic needs of users: the definition of basic queries; creating a working prototype; use a working prototype; view and improve the prototype; work with the final version of the prototype; use of readymade solutions - it is recommended to maximize the use of standard business automation technologies; use of third-party services to transfer control functions - an IS organization uses a specialized firm that performs control functions for the operation and development of an IS company.

Benefits: - guaranteed quality of service; - saving money; $\langle\mathrm{t} 0 /\rangle$ $<\mathrm{t} 1 />$ human resources.

\section{Gaps: - information leakage; dependence; loss of IT control.}

In the field of application, information systems are classified as follows: IS for research; IS of automated design; IS of organizational management.

Scientific ICs are used for automation of scientific activity, analysis of statistical information, experimental management. IS of automated designing is used for: development of new products and technologies for their production; various engineering calculations; creation of graphic documentation (drawings, diagrams, charts, etc.); simulation of projected objects.

The IS of organizational management is intended for automation of the functions of the administrative apparatus. These include the IP management of both industrial enterprises and non-industrial objects (banks, exchanges, insurance companies, hotels, etc.) and separate offices (office systems).

IS control processes are created to automate various technological processes. 


\subsection{Structural IS analysis technologies}

In the 70's and 80's. Twentieth century In the development of IS, a structured methodology was developed that provides developers with the strict formalized methods for describing IS and accepted technical solutions. It is based on visual graphic techniques: diagrams and charts are used to describe different types of IS models.

Under the structural analysis, it is common ground to refer to the method of research of a system, which begins with its general review, and then is detailed, providing for a hierarchical structure with an increasing number of levels. Its essence consists in partitioning the system into functional subsystems, which, in turn, are divided into subfunctions that are assigned to tasks, and so on. The process of breaking up continues to specific procedures. At the same time, the automated system retains a holistic view, in which all components are interconnected. When developing the system "bottom-up" from individual tasks to the whole system of integrity is lost, there are problems with the information compression of individual components. For such methods, a breakdown at the level of abstraction with a limitation of the number of elements at each of the levels is characteristic; limited context, which includes only essential parts at each level; the use of strict formal recording rules; consistent approximation to the final result.

All structural analysis methodologies are based on a number of general principles, the basic ones of which are the following: the principle of decomposition of the system, which is the principle of solving complex problems by breaking them down into a set of smaller, independent tasks that are easy to resolve; the principle of hierarchical ordering, which consists in the organization of the components of the task in the hierarchical structure. In addition, the important principles are: the principle of abstraction - is to allocate the essential aspects of the system and the separation from the non-essential; the principle of formalization lies in the need for a strict methodological approach to the problem of the principle of consistency - lies in the validity and consistency of the elements; the principle of structuring data - is that the data must be structured and hierarchically organized.

In the structural analysis, mainly two groups of tools are used, which illustrate the functions performed by the system, and the relationships 
between the data. The listed funds together give a complete description of the IS regardless of whether it exists or is being developed.

Visibility and clarity of structural analysis tools allowed developers and future users of the system to informally participate in its creation from the outset, to discuss and consolidate understanding of key technical solutions. However, the widespread use of this methodology and the imitation of its recommendations in the development of specific IS has been quite rare, as it is practically impossible for non-automated (manual) development. Indeed, manually it is very difficult to manually design and graphically present clear formal system specifications, check them for completeness and consistency, and moreover, to change. If you still manage to create a rigorous system of project documents, then their processing in the event of serious changes is practically impossible. Manual development usually caused the following problems: inadequate specification requirements; failure to detect errors in design decisions; low quality of documentation, which reduces performance; protracted cycle and unsatisfactory test results. On the other hand, IP developers historically have always been the last in a number of those who used computer technology to improve quality, reliability and productivity in their own work (the phenomenon of "The cobbler's children have no shoes").

These factors contributed to the emergence of software-technological tools of the special class - CASE-tools (Computer Aided Software Engineering), implementing CASE-technology for creating and maintaining IS.

CASE technology is an IS design methodology, as well as a set of tools that allow you to visualize the subject area, analyze this model at all stages of IS development and maintenance, and develop applications in accordance with the information needs of users. Most existing CASE-based tools are based on structured (mostly) or object-oriented analysis and design methodologies that use charts or text-based specifications to describe external requirements, relationships between system models, system behavior dynamics, and software architectures .

Each group of tools corresponds to certain types of models (diagrams), the most common of which are the following: SADT (Structured Analysis and Design Technique) models and corresponding functional charts; DFD (Data Flow Diagrams) of data flow diagrams; ERD (Entity - Relationship Diagrams) of the essence of the diagram. 
The SADT model provides a complete, accurate, and adequate description of a system that has a specific purpose. This purpose, which is called the model's purpose, stems from the formal definition of the model in SADT. SADT models use both natural and graphic languages. For the transfer of information about a particular system, the source of the natural language is the people who describe the system, and the source of the graphic language is the SADT method itself. The SADT graphical language provides the structure and exact semantics of the natural language model. The SADT graphic language organizes a natural language in a well defined and unambiguous way.

In terms of SADT, the model can describe either the functions of the system or its objects. Functional-oriented SADT models are called functional models, but object-oriented systems - data models. The functional model with the necessary degree of detail represents a system of functions, which, in turn, reflect their interconnections through the objects of the system.

Data models are dual to functional models and are a detailed description of system objects associated with system functions. The full SADT methodology supports the creation of multiple models for a more precise description of a complex system. Data Flow Diagrams (DFDs) are the main means of functional simulation of a projected system. For the DFD image, two different notations are traditionally used: Yourdon and Gane-Sarson. In accordance with the methodology, the system model is defined as a hierarchy of data flow diagrams that describe the process of transforming information from its input into the system before being issued to the user. With these diagrams, the system is divided into functional components (processes) and presented as a network linked by data flows. The main purpose of such tools is to demonstrate how each process converts incoming data on the output, as well as to identify the interactions between these processes.

Top-level hierarchy diagrams (contextual charts) define the main processes or subsystems of the IS with external inputs and outputs. They are detailed using lower-level charts. By creating a multilevel hierarchy of diagrams, this decomposition continues until such a level of decomposition is reached, on which processes become elementary and it is impossible to further elaborate them. 
When creating a data flow diagram, four basic concepts are used: data streams - abstractions used to model the transmission of information (or physical components) from one part of the system to another; processes of converting input data streams into output, the purpose of which is to produce output streams from the inputs in accordance with the action that specifies the process name; external nature (storage, storage) - is a material object outside the context of the system that is the source or data receiver and allows to specify on the specified areas data which will be stored in memory between processes; data storage (repository).

The task of the DFD set is to make the correct decomposition of the system in order to show the functioning of the system is clear and understandable at each level of detail. The process of building a model is divided into the following stages: the dismemberment of many requirements and their organization into the main functional groups; Identification of external objects with which the system should be connected; Identification of the main types of information circulating between the system and external objects; formation of the first level DFD based on the processes of the previous contextual diagram; DFD primary level requirements check. After decomposition of the main process for each subprocess, a similar table of internal events is constructed. The next step after defining a complete event table is to allocate data flows that are exchanged between processes and external entities. The easiest way to allocate them is to analyze the event tables. Events are converted into data streams from the event initiator to the requested process, and the reactions are in the reverse flow of events. After constructing input and output streams, internal flows are constructed in a similar way. For their selection for each of the internal processes are allocated suppliers and consumers of information. If the supplier or consumer of the information represents the process of storing or requesting information, then the data store for which the given process is an interface is entered. After constructing data flows, the diagram should be checked for completeness and consistency.

Entity-relationship model (ERD) are designed to develop data models and provide a standard way to identify data and interconnections between them. With ERD, the details of the data warehouses of the projected system are carried out, as well as the essence of the system and methods of their interaction, including identification of objects important for the subject 
domain of objects, properties of these objects (attributes) and their interrelations with other objects are documented.

An important place in the development of automated control systems are object-oriented methodologies, based on the object object decomposition, represented in the form of a set of objects that interact with each other through the transmission of messages. Authors of well-known methodologies Booch, Rumbaugh, and Jacobson have teamed up to develop a unified methodology called Unified Modeling Language (UML). When creating UML its authors were guided by the purpose of accelerating the evolution of the most popular methodologies in the direction of converging them with each other, summarizing the accumulated experience of their use, ensuring the stability of projects based on a single holistic method.

Heuristic methods have been widely used in automated control systems, and further progress in this direction is associated with the development and implementation of expert systems. Expert systems allow you to accumulate knowledge bases about the production process, about effective management solutions, and, on this basis, offer rational solutions to tasks that are inadequately formalized. The range of economics and mathematical models and methods is extremely wide. Their application is restrained by the complication of an adequate description of the production process, the receipt of solutions in the conditions of high dimensional tasks, as well as the lack of necessary for this case, the qualifications of managerial staff.

Below are models and methods for solving private tasks of enterprise management included in basic systems such as ERP: for solving strategic planning tasks, linear programming models are used; operational planning is usually built on the basis of network models. In this case, methods are used to calculate the critical path of the PERT; for solving the problems of forecasting demand and other economic processes, methods of regression analysis, analysis of time series, procedures for processing expert assessments are used; when solving tasks of planning sales volumes and production, methods of linear programming are used; the problem of forming the schedule of output can be formulated as a task of minimizing the total production cycle with restrictions on capacities, where the variables are the terms of launch (release). In basic systems such as ERP (Enterprise Resource Planning) there are procedures that solve this 
problem by generating, analyzing and screening options with simultaneous reductions in the number of variables in each iteration; the task of calculating the material needs for ensuring the timetable of output is solved on the basis of a model of disintegration, during which the calculation of the network structure describing the composition of the product. Operational production management in ERP is based on the application of priorities and heuristic methods for constructing work schedules. Normative base can be formed using statistical methods.

\subsection{Concept and models of life cycle (LC) of the IS}

The basis for the creation and use of software (SW) is the concept of its life cycle (LC). LC of IS - is the period of creation and use of IS, from the moment of the emergence of the need for IS and ending with the moment of its complete disengagement. LC is a model for creating and using software that reflects its different states, from the time the need arises in this software product and ending with the moment of its complete withdrawal from use among all users.

Traditionally, the following main stages of LC of software are distinguished: requirements analysis; designing; coding (programming); testing and debugging; operation and maintenance. Among the stages of the LC of IS, the following are distinguished: pre-project survey collection of materials for design, which involves the formulation of requirements, study of the object of automation, pre-presentation of the pre-project version of the IS, as well as analysis of materials and development of documentation, during which it is required to be given technically -economic substantiation with a technical task for the design of IS; design - preliminary design, which includes the choice of design decisions on aspects of the development of IS, description of the real components of IP, design and approval of a technical project (TP), detailed design, which includes the choice or development of mathematical methods or program algorithms, adjustment of database structures, creation of documentation for the delivery and installation of software products, the choice of a set of technical equipment with documentation for its installation, the development of a technical working project of IS (TWP), as well as the development of a methodology for the implementation of functions management by means of IS and description of the operating regulations of the management apparatus; development 
of IS, consisting of obtaining and installing technical and software tools, testing and proofing of software and development of instructions for the exploitation of software and hardware; the introduction of IS into operation - the introduction of technical means, the introduction of software tools, training and certification of personnel, experimental exploitation, the handing over and signing of acceptance-delivery acts; IS operation - daily operation, general maintenance of the entire project. The LC is formed in accordance with the principle of downstream design and, as a rule, is an iterative nature: the stages implemented, starting with the earliest, are cyclically repeated in accordance with changes in requirements and external conditions, the introduction of restrictions, etc. At each stage of the LC a certain set of documents and technical solutions is generated; At the same time, for each stage, the documents and decisions obtained in the previous step are initial. Each stage ends with the verification of the created documents and decisions in order to verify their compliance with the original.

The main regulatory document regulating the $\mathrm{LC}$ of the software is the international standard ISO/IEC 12207 (ISO - International Organization of Standardization, IEC - International Electrotechnical Commission). It defines the structure of the LC, which contains the processes, actions and tasks that must be performed during the creation of the software.

The structure of the LC of software according to the ISO/IEC 12207 standard is based on three groups of processes: the main processes of the LC of software (acquisition, supply, development, operation, maintenance); auxiliary processes that ensure implementation of the main processes (documentation, configuration management, quality assurance, verification, certification, evaluation, audit, problem solving); organizational processes (project management, project infrastructure, definition, evaluation and improvement of the LC itself, training).

The development includes all work on the creation of software and its components in accordance with the requirements. This includes the design and operational documentation, the preparation of materials necessary for testing the performance and quality of software products, materials necessary for the organization of training personnel, etc. Software development usually includes analysis, design and implementation (programming). 
Operation includes work on the implementation of components of software in operation. This process includes configuration of the database and user's workplaces, maintenance of operational documentation, training of personnel, and direct operation, including localization of problems and elimination of the causes of their occurrence, software modification within the established rules, preparation of proposals for improvement, development and modernization systems.

Project management involves planning and organizing work, creating teams of developers and monitoring the timing and quality of work performed. The technical and organizational support of the project includes the selection of methods and tools for the implementation of the project, the definition of methods for describing the intermediate state of development, the development of software methods and tools testing, personnel training, etc. Project quality assurance is associated with verification, testing, and testing problems.

Verification is the process of determining whether the current state of development, achieved at this stage, meets the requirements of this stage. The check allows you to evaluate the compliance of the development parameters with the initial requirements. The test partially matches the test, which involves identifying the differences between actual and expected results and evaluating the compliance of the characteristics with the initial requirements. In the process of implementation of the project, an important place is the identification, description and control of the configuration of individual components and the whole system as a whole.

Configuration management is one of the auxiliary processes that support the core processes of the software lifecycle, first of all, the processes of development and maintenance of software. When creating complex IC projects, consisting of many components, each of which can be varieties or versions, there is a problem accounting for their links and functions, the creation of a unified structure and the development of the entire system. Configuration management allows you to organize, systematically take into account and control the introduction of software changes at all stages of the LC. Currently, the general principles and recommendations for configuring, scheduling and managing software configurations are reflected in the draft ISO 12207-2.

Each process is characterized by certain tasks and methods of their solution, the initial data obtained in the previous stage, and the results. 
The results of the analysis, in particular, are functional models, information models and charts corresponding to them. The software LC is iterative: the results of the next stage often cause changes in design decisions made at earlier stages.

Existing LC models determine the order in which the stages are implemented during development, as well as the criteria for transition from stage to stage. Accordingly, cascading and spiral LC models were the most widespread.

Cascade model (70-80g.r.) - involves the transition to the next stage after the complete end of work of the previous stage.

Spiral model (86-90g.r.) - focuses on the initial stages of the LC: requirements analysis, design specifications, preliminary and detailed design. Each spiral round corresponds to a step-by-step model for creating a fragment or version of a software product, it specifies the purpose and characteristics of the project, determines its quality, the work of the next round of the spiral is planned. In this way, the details of the project are deepened and consistently specified, and as a result a valid option is selected that is to be implemented.

Experts note the following advantages of a spiral model: accumulation and reuse of software tools, models and prototypes; orientation on the development and modification of software in the process of its design; risk and cost analysis in the design process.

The main feature of the software industry is the concentration of complexity at the initial stages of the LC (analysis, design) with relatively low complexity and labor intensity of the subsequent stages. Moreover, unresolved issues and mistakes made at the stages of analysis and design, generate, at a later stage, difficult, often insoluble problems, and, ultimately, lead to the failure of the whole project. Consider these steps in more detail.

Requirements analysis is the first phase of software development, on which customer's requirements are specified, formalized and documented. In fact, at this stage, the answer is to the question: "What should the future system do?". It is here that the key to the success of the whole project lies. In the practice of creating large software systems, many examples of unsuccessful implementation of the project are known due to the incompleteness and uncertainty of the definition of system requirements. 
The list of requirements for the system being developed should include: a set of conditions under which the future system is intended to be operated (hardware and software resources provided to the system; external conditions of its operation; composition of people and works related to it); description of functions performed by the system; constraints in the design process (policy deadlines for completion of individual stages, available resources, organizational procedures and measures to protect information).

The purpose of the analysis is to transform the general, fuzzy knowledge about the requirements of the future system into as accurately as possible. At this stage, the following are determined: the architecture of the system, its functions, external conditions, the distribution of functions between hardware and software; interfaces and distribution of functions between a person and a system; requirements to the software and information components of the software, necessary hardware resources, requirements to the database, physical characteristics of the components of the software, their interfaces.

The main objective of computer-integrated technologies is the creation and operation of computer-integrated control systems that provide the solution of tasks for the coordination of the functioning of subsystems, the use of intelligent subsystems of decision support on the basis of databases and knowledge and management systems.

This kind of activity requires the knowledge of special software. At the same time, computer-integrated technologies are closely linked to systems of automatic control and automation of processes in various industries and production.

\section{REFERENCES}

1. Vitkup M.E., Petrenko V.V. Informatics and computer engineering (MSOffice in examples and problems with methods of their solution): Tutorial. Київ: Центр «Методика-информ», 2002. 351 с.

2. Марк Спортак, Френк Паппас и др- Компьютерные сети и сетевые технологии. PlatinumEdition: Пер. с англ. Санкт-Питербург.: ООО «ДиаСофтЮП», 2005. 720 с.

3. Билоусько В.С., Чуждан Т.И., Антипенский В.Е. Вычислительные машины и программирование: Практикум. Київ: Вища шк. Головное изд-во, 1987. 245 с. 
Information about the author: Medvediev M. H. Doctor of Technical Sciences, Professor,

Head at the General Engineering and Thermal Power Engineering Department of the V. I. Vernadsky Taurida National University 33, John McCain str., Kyiv, 02000, Ukraine 